\title{
Ações em inclusão digital baseadas nos princípios de liberdade, colaboração e compartilhamento do conhecimento
}

\author{
Vana Carvalho $^{1}$, Juliana Oliveira ${ }^{1}$, Josualdo Dias ${ }^{1}$, Débora Abdalla ${ }^{1}$ \\ ${ }^{1}$ Departamento de Ciência da Computação - Universidade Federal da Bahia (UFBA) \\ Av. Adhemar de Barros Campus Ondina - 40170-210 - Salvador - BA - Brasil \\ \{vanicah, julyms.85\}@gmail.com,\{josualdo.dias,abdalla\}@ufba.br
}

\begin{abstract}
This article describes the digital inclusion experiences carried out by the Programa Onda Digital (POD) highlighting how we use the principles of freedom, collaboration and knowledge sharing advocated by free software movements, open educational resources, open data and open access in this work denominated by movements of open technologies. The use of open technologies for digital inclusion brings diverse possibilities with great potential for democratization of knowledge, opportunities to access new technologies for disadvantaged communities and awaken to new ways of learning.
\end{abstract}

Resumo. Este artigo descreve as experiências de inclusão digital realizadas pelo Programa Onda Digital (POD) destacando a forma como utilizamos os princípios de liberdade, colaboração e compartilhamento de conhecimento defendidos pelos movimentos de software livre, recursos educacionais abertos, dados abertos e acesso aberto, neste trabalho denominados por movimentos de tecnologias abertas. A utilização de tecnologias abertas para inclusão digital traz diversas possibilidades com grande potencial para democratização do conhecimento, oportunidades de acesso à novas tecnologias para comunidades menos favorecidas e despertam para novas formas de aprender.

\section{Introdução}

As Tecnologias Digitais de Informação e Comunicação (TDIC) estão à serviço de diversas áreas do conhecimento, e empregadas nas mais variadas organizações, a exemplo das instituições de ensino. Tais tecnologias possibilitaram um avanço na educação, através do desenvolvimento de novos mecanismos para aprendizagem, no qual sua aplicação altera a lógica de ensinar e aprender, não mais centrada numa lógica única de transmissão de informações, promovendo assim uma transformação cultural da sociedade contemporânea [Pretto and Bonilla 2011].

Junto a essas transformações, surge a mudança cultural na comunicação agregada à importante aceitação e apropriação das tecnologias digitais pela sociedade, e neste processo evolucionário e revolucionário, surgem movimentos como o de software livre, dados abertos e o de acesso aberto, baseados nos princípios de liberdade, colaboração e compartilhamento do conhecimento.

A educação sendo uma fonte de crescimento socioeconômico e aplicada com a tecnologia, trouxe outra perspectiva em relação a busca pelo conhecimento, criando um olhar sobre a inclusão digital como uma resposta à sociedade, de modo que ela tenha acesso às tecnologias digitais abertas. [Filho 2003] afirma que as escolas e universidades 
VI Congresso Brasileiro de Informática na Educação (CBIE 2017)

Anais do XXIII Workshop de Informática na Escola (WIE 2017)

são componentes essenciais para inclusão digital, pois nessas instituições seus protagonistas (professores, alunos, pesquisadores) atuam para disseminação do conhecimento. $\mathrm{E}$ [Canez and Severo 2016], indica que na educação, as novas tecnologias são vistas como ferramentas que servem para otimizar a prática pedagógica, proporcionando aulas mais dinâmicas e mais interessantes, onde são criados novos espaços que vão além da sala de aula.

Acreditamos que os movimentos software livre, REA, dados abertos e acesso aberto, neste trabalho denominados por movimentos de tecnologias abertas, devem trabalhar juntos para que a educação e a ciência sejam de conhecimento de todos e que possam utilizá-las para construção de uma sociedade mais integrada e conhecedora dos seus direitos e deveres. Como exemplo, na Universidade Federal da Bahia (UFBA), temse o Programa Onda Digital (POD), com propostas de ações para inclusão digital, no formato de oficinas e cursos, apresentando as tecnologias digitais abertas de forma que os usuários tenham liberdade de escolher e usar o que melhor lhe aprouver.

Dessa forma, o artigo segue organizado em mais três seções: na Seção 2 apresentamos uma discussão sobre os movimentos de tecnologias abertas, na Seção 3 descrevemos a metodologia utilizada pelo POD para inserir nas suas ações em inclusão digital a lógica do movimentos de tecnologias abertas, na Seção 4 destacamos experiências e análise dos resultados dessa simbiose. Por fim, nas considerações finais enfatizamos o princípio dos movimentos de tecnologias abertas e atividades futuras para sua popularização e ações de inclusão digital que estabelecem uma relação entre as tecnologias concomitantemente com a sociedade e a academia.

\section{Movimentos de Tecnologias Abertas}

Os movimentos de tecnologias abertas, estão fundamentalmente relacionados com a disseminação do conhecimento, comprometidos com o acesso à educação e à informação. Entre esses movimentos, o movimento do software livre, é o que mais se destaca. É definido por [Alencar et al. 2009] como um movimento político de base tecnológica que pode ser considerado como um dos catalisadores das mudanças ligadas ao mundo digital. No aspecto filosófico, o software livre baseia-se nas liberdades de: executar o programa, para qualquer propósito; estudar como o programa funciona, e adaptá-lo para as suas necessidades; redistribuir cópias; aperfeiçoar o programa, e distribuir os seus aperfeiçoamentos.

O movimento de software livre pode ser visto como uma possibilidade de novas apropriações das TDIC, com enriquecimento nas propostas de ensino e aprendizagem que passarão a atuar na (des)construção de modelos hegemônicos, construção e compartilhamento de conhecimentos em uma perspectiva que valorize diversidades e atenda às necessidades dos variados grupos sociais. Em uma abordagem freiriana, educadores devem compreender a arte de ensinar não como mera transferência de conhecimento, mas sim como mecanismo capaz de criar possibilidades para a produção e construção do conhecimento, numa perspectiva de autoria e transformação [Freire 2005].

Silveira (2003) apresenta alguns argumentos para justificar a adoção de softwares livres nas políticas públicas de inclusão digital, tais como:

- redução de custos para o Estado com a aquisição de licenças, podendo investir tais recursos com a formação e capacitação, treinamento e educação digital; 
VI Congresso Brasileiro de Informática na Educação (CBIE 2017)

Anais do XXIII Workshop de Informática na Escola (WIE 2017)

- estímulo à criatividade com o desenvolvimento de soluções adequadas aos interesses de empresas e comunidades, contribuindo para sustentabilidade e potencializando o desenvolvimento sociocultural e econômico local.

Além disso, [Silveira 2003], enfatiza que:

“...não é correto utilizar dinheiro público para formar e alfabetizar digitalmente os cidadãos em uma linguagem proprietária de um monopólio privado transnacional. Mesmo que as licenças de uso de um sistema operacional proprietário sejam doadas gratuitamente para os programas de inclusão digital, na realidade, o Estado estaria pagando seus professores, monitores e instrutores para adestrar e treinar usuários para aquela empresa." (pág. 22)

O movimento do Recurso Educacional Aberto (REA), no cenário da educação, assume um papel importante: o de abrir o acesso ao conhecimento para estudantes formalmente matriculados e estudantes informais [Silva 2015], além de ser múltiplo, podendo ser tanto recursos didáticos para professores como também recursos voltados à aprendizagem do usuário, além de cursos completos, vídeos, livros e software. A UNESCO [Col 2011] define REA como recursos de ensino, de aprendizagem e de pesquisa, de domínio público ou liberados, sob licença de propriedade intelectual que permitem utilização gratuita e reutilização por outras pessoas. Inspirado na filosofia do software livre, o REA permite que o usuário final, possa: fazer download; associar os recursos a outros criando novas obras; remixar.

$\mathrm{Na}$ definição de Acesso Aberto pela [Initiative et al. 2012], é disponibilizar gratuitamente na internet pública, para que qualquer pessoa leia, baixe, copie, distribua, imprima ou pesquise, contanto que confira aos autores a integridade e o direito sobre o trabalho. Os projetos baseados no movimento de acesso aberto, [Furnival and Hubbard 2011] propiciou a criação e o apoio de repositórios institucionais (RI) nos quais os pesquisadores podem depositar seus preprints e postprints (versões de artigos pré e pós-revisão por pares e subsequente publicação), os RI segundo [Leite et al. 2012], contempla a reunião, armazenamento, organização, preservação, recuperação e, sobretudo, a disseminação da informação científica produzida na instituição. Essas características permitem que os materiais produzidos em ações de inclusão digital, sejam depositadas no repositório e possibilitem o acesso aberto a essa produção por qualquer pessoa.

O movimento de Dados Abertos segue os princípios do acesso aberto, mas no tocante aos dados que podem ser livremente utilizados, reutilizados e redistribuídos por qualquer pessoa. A origem dos dados abertos, segundo [Possamai 2016], remonta à articulação pela promoção de softwares de código abertos na década de 70 em diante, em oposição às restrições impostas pelos direitos de propriedade intelectual às possibilidades de colaboração. Esse conceito suscita a possibilidade de qualquer pessoa, acessá-los e utilizar quaisquer softwares que permita a leitura e edição desses dados como lhe aprouver, tratando assim de um questão de inclusão.

A relação entre os movimentos acima apresentados, parte da filosofia do "aberto" das tecnologias digitais abertas, e convergem para ações de inclusão digital. Eles se apresentam como um aporte para que a sociedade tenha acesso aos dados, tal como às 
produções científicas e aos sistemas computacionais. A inclusão digital destaca-se nesse contexto, pois firma a necessidade de se multiplicar o conhecimento sobre os conceitos tecnológicos e como a sociedade pode se transformar a partir disso.

Com o papel de transformar a sociedade, os movimentos de software livre, REA, acesso aberto e dados abertos apontam o quanto é importante discutir sobre o acesso à informação, à tecnologia e à educação; se permitir pensar sobre o que pode ser feito com as informações e tecnologias disponíveis, apontando também a importância da colaboração e compartilhamento, que é a base filosófica destes movimentos. E, mesmo com propostas específicas, os movimentos de tecnologias abertas, porém, convergem nos quesitos de adaptar ou remixar uma cópia da obra na produção de novos resultados, com atribuição dos créditos ao autor ou criador da obra inicial. Outro ponto importante é que o uso dos dados e tecnologia abertas não estão sujeitas a qualquer cobrança financeira para acessá-la, fato este que beneficia especialmente os projetos de inclusão digital. Esta discussão enfatiza que os movimentos de tecnologias abertas devem trabalhar juntos para que a educação e a ciência sejam de conhecimento do público e que possam utilizá-las para construção de uma sociedade mais integrada e conhecedora dos seus direitos e deveres.

\section{Metodologia}

Pautado na filosofia do software livre, o POD, tem a missão de contribuir com a inclusão sociodigital na Bahia, envolvendo a Universidade em ações educativas, oportunizando a disseminação do conhecimento por meio de tecnologias livres e desenvolvendo ações junto à comunidade em situação de vulnerabilidade socioeconômica de Salvador e Região Metropolitana. Como parte integrante do Programa, o Projeto Onda Solidária de Inclusão Digital, promove, gratuitamente, cursos de extensão presenciais de curta duração (em virtude do período letivo da universidade) com o apoio dos estudantes de graduação e pós-graduação que atuam como estudantes educadores.

Prezamos pela utilização de tecnologias digitais abertas nas diversas fases das ações promovidas, tanto naquelas desenvolvidas dentro da universidade quanto àquelas realizadas nas instituições parceiras, às quais estimulamos e sensibilizamos para o uso destas tecnologias, dando suporte na instalação, configuração e orientações para uso adequado.

As ações são realizadas em parceria com entidades que coadunam com os princípios do Programa, tais como organizações não governamentais, associações civis, escolas e espaços de acesso público e gratuito às tecnologias da informação e comunicação, utilizando-se da infraestrutura destes espaços para promoção de atividades que compartilham e constroem conhecimentos sobre cultura digital, software livre, dados abertos, remix e trabalho colaborativo. Associado a isto, são lançados semestralmente editais de seleção para cursos de extensão na área de tecnologia destinados ao público de modo geral. Nesses casos, os cursos são realizados em espaços da própria universidade, oportunizando que jovens e adultos, que por vezes não tinham perspectiva de ingressar no ensino superior, possam conhecer e ter contato direto com o ambiente universitário e despertar para uma carreira profissional.

Os participantes dos cursos que conseguem atingir frequência mínima de $75 \%$ e tem aproveitamento avaliado como satisfatório pelos instrutores, recebem certificado de participação com carga horária expedido pela Pró-Reitoria de Extensão da UFBA 
VI Congresso Brasileiro de Informática na Educação (CBIE 2017)

Anais do XXIII Workshop de Informática na Escola (WIE 2017)

(PROEXT-UFBA). Ainda no processo de seleção é realizada uma avaliação diagnóstica por meio de questionário de conhecimentos específicos e entrevista presencial, de modo a identificar as particularidades de cada um e oferecer cursos que atendam às demandas dos alunos, seus interesses e que levem em conta as experiências desses sujeitos. Ao longo do curso são observados aspectos como: participação nas discussões em sala e atividades práticas, realização das atividades online, pontualidade e, colaboração nos projetos em grupo. Desta forma, ao final do curso podemos avaliar o desenvolvimento e aprendizado de cada aluno e constatar se o mesmo está apto para atuar de acordo com os objetivos previstos.

Ao final dos cursos de extensão, os alunos são motivados a desenvolver um projeto final, individual ou em grupo, com temática escolhida pelos alunos ou sugerida pelos instrutores, no qual eles devem utilizar o máximo de recursos aprendidos durante o curso, auxiliando na avaliação do aprendizado e, também, potencializando a transformação desses sujeitos, de consumidores para produtores de conteúdos.

Os cursos são ministrados por alunos de graduação e pós-graduação da UFBA matriculados no componente curricular, modalidade disciplina, intitulado Ação Curricular em Comunidade e em Sociedade (ACCS), iniciativa pioneira no Brasil mantida pela PROEXT-UFBA. Na ACCS Onda Solidária de Inclusão Digital - Tecnologia a Serviço da Cidadania (MATC53), a maior participação de alunos da área de computação e tecnologia (bolsistas e voluntários do POD), fortalece as ações em prol da utilização de tecnologias livres no processo de inclusão digital.

Destacamos dentre as ações desenvolvidas as seguintes atividades: Curso de Internet e Tecnologias Abertas, Curso de Iniciação à Programação de Computadores, Curso de Games com Uso de Software Livre e Oficinas Itinerantes de Ciberativismo.

O Curso de Internet e Tecnologias Abertas (CITA) tem como objetivo introduzir os participantes nos conhecimentos de informática básica e orientar sobre o uso seguro da internet, capacitando-os na utilização dos principais aplicativos de escritório, com o propósito de aprimorar as competências e habilidades de jovens e adultos no uso das tecnologias digitais para a formação de um perfil de cidadão conectado e contemporâneo, além de contribuir para inserção no mercado de trabalho. O CITA é dividido em 6 (seis) tópicos e estruturado em 12 aulas, com carga horária total de 36 horas. Os tópicos trabalhados são: familiarização com o sistema operacional livre, internet (navegadores, buscadores e downloads), computação em nuvem (armazenamento e cibersegurança), fluência em dispositivos móveis, uso de e-mails e a suíte de escritório LibreOffice (editor de texto, planilha eletrônica e editor de apresentação).

O Curso de Iniciação à Programação de Computadores (CIPROG) tem como objetivo introduzir aos participantes noções de programação com enfoque no desenvolvimento do raciocínio computacional de forma problematizada e contextualizada, incentivo ao desenvolvimento lógico-matemático e estímulo à capacidade de resolução de problemas. O CIPROG é dividido em 6 (seis) tópicos e estruturado em 12 aulas, com carga horária total de 36 horas. Os tópicos trabalhados são: raciocínio lógico, algoritmos, expressões aritméticas, desvios condicionais, laços de repetição e vetores. Estes são discutidos com a utilização de recursos computacionais livres voltados para o ensino de programação. Durante o curso utiliza-se a pseudolinguagem Portugol e a linguagem de programação C. 
VI Congresso Brasileiro de Informática na Educação (CBIE 2017)

Anais do XXIII Workshop de Informática na Escola (WIE 2017)

O Curso de Games com Uso de Software Livre (CGUSL) tem como objetivo aprimorar os conhecimentos em programação e orientação a objetos dos participantes, com a utilização da linguagem de programação JavaScript para o desenvolvimento de jogos utilizando a biblioteca Phaser e o software Brackets. O CGUSL é dividido em 7 (sete) tópicos e estruturado em 10 aulas, com carga horária total de 30 horas. Os tópicos trabalhados são: conceitos básicos de lógica de programação e raciocínio lógico matemático, mercado de games no Brasil, jogos independentes, recursos livres utilizados e desenvolvimento de jogos.

A Oficina Itinerante de Ciberativismo tem o intuito de engajar cidadãos no exercício da cidadania por meio de aproximação com os agentes políticos, participação ativa, controle social e combate à corrupção nos ambientes digitais, utilizando-se de redes sociais, canais de informações adequados, portais de dados e transparência e outras ferramentas de fiscalização disponíveis. A oficina amplia a criatividade, gera inovação e reinventa o ativismo frente às novas tendências comunicacionais. As oficinas tem 2 (duas) horas de carga horária e trabalha com tópicos como: ativismo, cibercultura, ciberativismo, cidadania e participação social, comunicação entre população e governantes, mídia cidadã, canais de fiscalização e e-gov.

O Ambiente Virtual de Aprendizagem (AVA) Moodle é um software livre utilizado nos cursos como estratégia complementar ao ensino presencial. $\mathrm{O}$ ambiente é personalizado e configurado de modo a atender às necessidades das diversas turmas participantes de cursos ao longo do semestre. No ambiente são disponibilizados os materiais didáticos, leituras complementares, atividades e serve como canal para comunicação da turma com instrutores e vice-versa. Os cursos também são gamificados de modo a tornar a aprendizagem mais interessante e lúdica.

Os planos de aula e materiais didáticos são construídos utilizando-se de editores de texto e de apresentação online, permitindo o compartilhamento entre editores, edição simultânea, controle de versões e criação de cópias de forma simplificada. Os produtos finais, partindo do conceito de REA, com o aporte de uma licença Creative Commons do tipo atribuição-não-comercial-compartilha-igual (BY-NC-SA) são disponibilizados no site do Programa em duas opções: no formato Portable Document Format (PDF) ou o link público do arquivo na Web com permissão de visualização, possibilitando a criação de cópias ou o download em outros formatos, facilitando a troca, uso e reuso destes recursos educacionais abertos.

\section{Experiências e Análise dos dados}

O público atendido pelo POSID é diversificado, abrangendo pessoas em situação de vulnerabilidade socioeconômica, com idades que variam de 9 a 70 anos de idade, oriundas dos mais diversos bairros de Salvador, com realidades, experiências, limitações e interesses peculiares. Tais peculiaridades justificam a adoção de tecnologias digitais abertas na concepção dos cursos e oficinas promovidas pelo projeto, permitindo adaptações e reformulações conforme o cenário social e tecnológico presente.

Publicar os materiais produzidos como REA, requer o envolvimento e capacitação dos integrantes da equipe sobre as licenças e como atribuí-las em suas produções, além do entendimento sobre a base dos direitos autorais, para sua devida aplicação. Essa dinâmica serve como uma forma de incentivar os participantes do grupo a colaborarem entre si na 
VI Congresso Brasileiro de Informática na Educação (CBIE 2017)

Anais do XXIII Workshop de Informática na Escola (WIE 2017)

construção de novos mecanismos e materiais, em prol de uma educação libertadora e transformadora. Além disso, a produção desses materiais requer a constante busca por conteúdos multimídia (imagens, vídeos e áudios) que também possam ser incluídos como REA sem infringir leis de direitos autorais. Sendo esta uma das dificuldades constatadas por [Mazzardo et al. 2016], a falta de cultura em observar os direitos autorais e as licenças, bem como identificar o REA, se confirmando um desafio para sua integração e consolidação na construção de materiais e atividades didáticas.

No que tange ao uso dos softwares livres, os materiais de divulgação dos cursos de extensão são produzidos utilizando os Inkscape e Gimp. Nos laboratórios de informática da universidade ou comunidades parceiras, em que as ações são realizadas, utiliza-se o sistema operacional livre GNU/Linux, na distro Debian ou Ubuntu. Em todos os cursos e oficinas realizadas é dedicado um momento para discutir os softwares livres: o que são? por que utilizamos? quem utiliza? como obter? quais as vantagens? Nessa oportunidade, desvendamos alguns mitos, inclusive no que diz respeito às críticas que capacitar com softwares livres não prepara para o mercado de trabalho, fortemente dominado pelo monopólio dos softwares proprietários.

Compreendemos que se uma pessoa entende o que é e para que serve um software editor de texto, planilha eletrônica ou editor de apresentações e aprende a utilizá-los, entendem seu funcionamento e sabe escolher o recurso mais adequado para cada situação, ela estará preparada para usufruir daquele recurso e não foi simplesmente "programada" para usar a tecnologia de uma empresa X, Y ou Z. Nos depoimentos de participantes dos cursos, podemos perceber que apesar da "estranheza" inicial, natural em qualquer situação na qual nos deparamos com algo novo, o software livre detém as affordances necessárias para que os usuários percebam como podem operá-lo e manipulá-lo:

"Não houve dificuldade pois já tinha feito cursos na área de informática, então ao ser apresentada ao linux, pude associar os métodos utilizados." (participante de curso em 2014.2, grifo nosso)

"No início foi estranho por não ter contato antes. Mas, ao passar das aulas isso foi mudando e mostrando a facilidade de utilizar softwares livres." (participante de curso em 2016.1)

Constatamos que embora o número de pessoas que possuem computador, acesso à internet e smartphones em suas residências tenha aumentado nos últimos anos [Barbosa 2016], isso só contempla uma parte do aspecto de inclusão digital. O outro lado da inclusão digital, ou mesmo a exclusão digital, se expressa nos procedimentos de letramento e alfabetização digital, que possibilita que as pessoas possam utilizar seus equipamentos de maneira mais efetiva, podendo usufruir de recursos e funcionalidades que facilitem seu dia a dia, e na geração de novas oportunidades pessoal, social e profissional.

Como alternativa à exclusão digital, o software livre por oferecer ambientes gráficos mais leves, podem ser instalados em hardwares considerados "obsoletos", gerando economia e redução de problemas ambientais, além de oportunizar que comunidades menos favorecidas possam apropriar-se das novas tecnologias a baixo custo. Alguns depoimentos já demonstram que os participantes do curso enxergam o potencial dos softwares livres na democratização do conhecimento: 
VI Congresso Brasileiro de Informática na Educação (CBIE 2017)

Anais do XXIII Workshop de Informática na Escola (WIE 2017)

"Certamente que a utilização de software livre traz um diferencial porque; democratiza o conhecimento e o acesso a tecnologia e informação, e por isso também, foi impactaste no meu aprendizado.” (participante de curso em 2016.1)

"acho q sera uma tendencia a partir do momento a informação começar a alcançar público mais humilde da população.” (participante de curso em 2016.1)

No semestre 2015.2, promovemos no CITA uma aula exclusiva para apresentar a enciclopédia livre, Wikipédia, e como contribuir. Os participantes demonstraram bastante interesse no tema e muitos ficaram surpresos com a possibilidade de editar e traduzir artigos da enciclopédia. A atividade serviu para quebrar mitos sobre a não credibilidade dos conteúdos da Wikipédia. Alguns depoimentos apontam a perspectiva dos participantes:

"Através do palestrante aprendi que é importante contribuir com editacões no wikipédia pois varias pessoas no mundo usa o site em buscas de informações e é de extrema importancia, aprendi coisas que não sabia, como a traducão de conteudos $e$ tambem pela primeira vez editei!"

"Ficou claro pra mim que é muito importante compartilhar nossos conhecimentos para as demais pessoas, aprendi como editar um texto no wikipédia, a traduzi-lo para pessoas fora do nosso país poder visualizar também, e que também não devemos publicar informações falsas lá,primeiro por termos plena consciência que este ato é incorreto e segundo pois pessoas estarão visualizando todas aquelas informações podendo até excluí-la."

Nas edições do CIPROG além de todos os conhecimentos partilhados sobre software livre, ao utilizarmos o REA Scratch no ensino de programação, incentivamos os alunos a colaborar com projetos já existentes ou manter seus projetos na comunidade de aprendizagem criativa do Scratch (versão online) como incentivo à prática do remix. $\mathrm{Na}$ última edição do CIPROG, no semestre 2016.2, promovemos oficinas sobre programação com o hardware livre Arduíno. A atividade teve boa aceitação e alguns grupos dos projetos finais, como já aconteceu em edições anteriores do CIPROG escolheram fazer o projeto usando Arduíno.

Na primeira edição do CGUSL, realizada no semestre 2016.2, ao final do curso colocamos os materiais de aula e os jogos dos alunos no ambiente GitHub ${ }^{1}$ na perspectiva de que em outras edições, interessados possam melhorar as primeiras versões do jogo ou criar novos jogos baseados nas ideias de ex-participantes do curso.

Ao final dos cursos, quando questionados se a utilização de softwares livres trouxe algum diferencial para o curso e para o aprendizado, em média, mais de $90 \%$ dos participantes responderam positivamente e, alguns, relatam que já estão usando softwares livres em seus computadores pessoais. Em relação ao AVA Moodle, em média, cerca de $85 \%$ dos participantes dos cursos não conheciam o ambiente antes do curso.

O AVA Moodle além de complementar o ensino presencial possibilita que mais pessoas conheçam um ambiente amplamente utilizado em cursos à distância. E esse contato inicial com o ambiente permite que elas estejam aptas para utilizá-lo em outras oportunidades com maior destreza. Ao final de cada curso, o espaço correspondente do curso no Moodle fica com acesso aberto para visitantes, possibilitando que outras pessoas te-

\footnotetext{
${ }^{1}$ https://diegozabot.github.io/Game-Course-2016.2/
} 
VI Congresso Brasileiro de Informática na Educação (CBIE 2017)

Anais do XXIII Workshop de Informática na Escola (WIE 2017)

nham acesso aos materiais, discussões e atividades propostas.

Segundo pesquisa da Fundação Getúlio Vargas [Ruediger et al. 2017], o Brasil já é o $8^{\circ}$ país no ranking mundial de divulgação de dados da administração pública, conquista assegurada pela Lei de Acesso à Informação, a Lei n ${ }^{0} 12.527 / 2011$. Porém, ainda é difícil para o cidadão "comum" encontrar e entender os dados disponíveis. Nesse sentido, na oficina itinerante de ciberativismo trazemos aos participantes a aplicação do conceito de acesso aberto e dados abertos, enfatizando a importância do cidadão perceber o seu entorno e se apropriar nas questões pertinentes ao seu ambiente social, de forma a usar as mídias digitais em prol de um bem comum.

A utilização de tecnologias digitais abertas para inclusão digital traz diversas possibilidades que mesmo em estágios iniciais tem grande potencial para democratização do conhecimento, oportunidades de acesso à novas tecnologias para comunidades menos favorecidas e despertam para novas formas de aprender.

\section{Considerações Finais}

Discutimos no artigo a experiência do Programa Onda Digital em realizar ações de inclusão digital fazendo uso dos princípios do movimento de software livre, no que concerne a liberdade de uso, extensível aos demais movimentos de tecnologia aberta: REA, acesso aberto e dados abertos. Esses movimentos representam mudanças no comportamento da sociedade e a Universidade tem papel fundamental nessa transformação, por meio do fomento de ações de extensão que possibilitam através de tecnologias digitais abertas que as pessoas consigam depreender e usar os dados disponíveis, com conhecimento para discutir e reivindicar com apropriação.

Como atividades futuras de popularização dos movimentos de tecnologias abertas, podemos destacar:

- inserção das produções científicas e com fins educacionais produzidos pelo Programa no Repositório Institucional da UFBA, sob a licença Creative Commons mais adequada para cada caso;

- adoção de uma solução aberta para aplicação de questionários online, utilizados nos processos seletivos dos cursos de extensão;

- realização de oficinas de desenvolvimento de bots, pacote de stickers e jogos no aplicativo Telegram;

- realização de oficinas de edição e tradução de verbetes da Wikipédia;

- disponibilização dos projetos finais dos participantes dos cursos de extensão em repositórios que possibilitem a colaboração e o remix.

Apontamos que as práticas disseminadas pelos movimentos devem ser discutidas em ações de inclusão digital para que alcance a sociedade como um todo e que a Universidade forneça o suporte necessário para que tais atividades sejam discutidas, construídas e apresentadas por sua comunidade.

As ações de inclusão digital realizadas pelo Programa, configuram-se em uma alteração na forma como o usuário interage com as tecnologias, despertando para novas formas de aprender, caracterizando a importância e influência que os movimentos podem ter sobre uma sociedade crítica e, pensante. Esta análise busca estabelecer uma sinergia 
VI Congresso Brasileiro de Informática na Educação (CBIE 2017)

Anais do XXIII Workshop de Informática na Escola (WIE 2017)

entre os movimentos de tecnologias abertas, a universidade e as ações de inclusão digital, na perspectiva de apropriação social da ciência e tecnologia em prol de um bem comum, de forma consciente e responsável, envolvendo princípios de colaboração, remix, autoria e inovação.

\section{Referências}

Alencar, A. F. d., Machado, M. B., Evangelista, R., Silveira, S. A. d., and Aguiar, V. M. (2009). Software livre cultura hacker e ecossistema da colaboração. Produção de terceiros sobre Paulo Freire; Série Livros.

Barbosa, A. F. (2016). Pesquisa sobre o uso das tecnologias de informação e comunicação nos domicílios brasileiros [livro eletrônico]: Tic domicílios 2015.

Canez, A. V. and Severo, C. E. (2016). Implicações do software livre no ensino e aprendizagem: um estudo de caso no ensino médio politécnico. In Anais do Workshop de Informática na Escola, volume 22, page 476.

Col, U. (2011). Guidelines for open educational resources (oer) in higher education.

Filho, A. M. d. S. (2003). Os três pilares da inclusão digital. Revista Espaço Acadêmico, 3(24):5.

Freire, P. (2005). Pedagogia da autonomia: saberes necessários à prática educativa. são paulo: Paz e terra, 1996. Coleção leitura.

Furnival, A. C. and Hubbard, B. (2011). Acesso aberto às publicações científicas: vantagens, políticas e advocacy. InCID: Revista de Ciência da Informação e Documentação, 2(2):160-177.

Initiative, B. O. A. et al. (2012). Ten years on from the budapest open access initiative: setting the default to open. Erişim adresi http://www. budapestopenaccessinitiative. org/boai-10-recommendations.

Leite, F., Amaro, B., Batista, T., and Costa, M. (2012). Boas práticas para a construção de repositórios institucionais da produção científica. Brasília: Ibict.

Mazzardo, M. D., Nobre, A., and Mallmann, E. M. (2016). Small open online course com professores do ensino médio: desafios para integrar rea nos materiais e atividades didáticas. In Anais do Workshop de Informática na Escola, volume 22, page 669.

Possamai, A. J. (2016). Dados abertos no governo federal brasileiro: desafios de transparência e interoperabilidade.

Pretto, N. D. L. and Bonilla, M. H. S. (2011). Inclusão digital: polêmica contemporânea. SciELO.

Ruediger, M. A., Grassi, A., Falconiery, A., Barbosa, B., Fernandes, J. d. M., and Oliveira, W. (2017). Open data index for brazil. Technical report, FGV DAPP.

Silva, D. d. N. (2015). Recursos educacionais abertos como fontes de informação. Encontros Bibli: revista eletrônica de biblioteconomia e ciência da informação, 20(44).

Silveira, S. A. d. (2003). Inclusão digital, software livre e globalização contrahegemônica. Software Livre e Inclusao Digital-Organizadores: Sergio Amadeu de Silveira e Joao Cassino, 7:11. 